\title{
Application of a diagnostic framework based on the concepts of Workload Control to identify the problems related to the delivery reliability in a company of the aeronautical maintenance sector
}

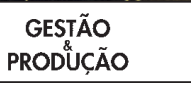

ISSN 0104-530X (Print) ISSN 1806-9649 (Online)

\section{Aplicação de um framework de diagnostico baseado nos conceitos de Workload Control para identificação dos problemas relacionados à confiabilidade de entrega em uma empresa do setor de manutenção aeronáutica}

\author{
Tatiana Kimura Kodama ${ }^{1}$ (D) \\ Matthias Thürer ${ }^{2}$ \\ Moacir Godinho Filho'
}

\begin{abstract}
How to cite: Kodama, T. K., Thürer, M., \& Godinho Filho, M. Application of a diagnostic framework based on the concepts of Workload Control to identify the problems related to the delivery reliability in a company of the aeronautical maintenance sector. Gestão \& Produção, 26(4), e3672. https://doi.org/10.1590/0104-530X3672-19
\end{abstract}

\begin{abstract}
The improvement in the performance of delivery reliability in Make-To-Order (MTO) companies is an important competitive criterion in the current market environment. This research investigates how a diagnostic framework can be used to identify how delivery reliability is influenced by Production Planning and Control (PPC) decisions. For the development of this research, a case study was carried out in two workshops of a company of the aeronautical maintenance sector. In the workshops studied, delivery reliability performance is influenced by the erroneous determination of due dates (focus on DP-Date time Promissing), with the capabilities being overestimated. The main contribution of the application framework presented is an aggregate analysis of the behavior of the lateness in a certain period of time. Future research should develop criteria for subset creation and further study the framework in order to improve it.
\end{abstract}

Keywords: Delivery reliability; Production planning control; Shop floor supervision

Resumo: A melhoria no desempenho da confiabilidade de entrega em empresas que produzem por encomenda (Make-to- Order-MTO) é um importante critério competitivo na atual conjuntura de mercado. Esta pesquisa investiga como um framework de diagnostico pode ser usado para identificar como a confiabilidade de entrega é influenciada pelas decisões de Planejamento e Controle da Produção (PCP). Para o desenvolvimento desta pesquisa, realizou-se um estudo de caso em duas oficinas de uma empresa do setor de manutenção aeronáutica. Nas oficinas estudadas, o desempenho da confiabilidade de entrega é influenciado pela determinação errônea das datas de entrega (foco em DP-Date Promissing), sendo as capacidades superestimadas. A principal contribuição da aplicação framework apresentado é uma análise agregada do comportamento dos atrasos em um determinado período de tempo. As pesquisas futuras devem desenvolver critérios para a criação de subsets e estudar mais profundamente o framework com o intuito de aprimorá-lo.

Palavras-chave: Confiabilidade; Planejamento e controle da produção; Supervisão de chão-de-fábrica.

\footnotetext{
${ }^{1}$ Planejamento e Controle de Sistemas Produtivos, Departamento de Engenharia de Produção, Universidade Federal de São Carlos UFSCar, Rodovia Washington Luis, Km 235, CP 676, Monjolinho, CEP 13565-905, São Carlos, SP, Brasil, e-mail: kimura.tatiana@ gmail.com; moacir@dep.ufscar.br

${ }^{2}$ School of Intelligent Systems Science and Engineering, Jinan University, Jinan University, Zhuhai Campus, 519070, Zhuhai, PR, China, e-mail: matthiasthurer@workloadcontrol.com
} 


\section{Introduction}

In Make-to-Order (MTO) companies, prices and delivery times are determined for each job and are considered to be crucial factors for winning the order (Kingsman \& Hendry, 2002; Stevenson et al., 2005). Thurer \& Godinho (2012) state that one of the most important operational competencies for MTO companies is the ability to achieve a reduced and predictable lead time in order to keep the promise to the customer, while reducing delivery time may be a determining criterion for winning the job. Therefore, the decisions taken by Production Planning and Control (PPC) must be aligned to achieve this goal.

According to Kingsman \& Hendry (2002), PPC decisions that influence delivery reliability are based on input and output controls. As stated by Soepenberg et al. (2008), the performance of delivery reliability needs to be traced back to the decisions of the PPC. In order to improve this performance, it is necessary to recognize the causes of lateness if they originate in the determining the Delivery time Promising (DP) or in the Realisation Process (RP) (Soepenberg, 2010).

Among the approaches proposed in the literature, Workload Control (WLC) is considered one of the main solutions for PPC in MTO companies (Kingsman \& Hendry, 2002; Stevenson et al., 2005). This methodology allows production and inventory costs to be reduced, resulting in competitive prices and reliable delivery dates (Due Dates - $D D$ ) (Kingsman $\&$ Hendry, 2002). Soepenberg et al. (2012b), based on the concepts of WLC, proposed a framework with the objective to diagnose the cause of performance of delivery reliability influenced by PPC decisions. However, according to the authors, the framework needs to be refined for its practical application.
This study has exactly the objective of applying the framework proposed by Soepenberg et al. (2012b) through a case study at a MTO company in the aeronautical maintenance industry.

The remaining of this paper is structured as follows: Section 2 presents the theoretical framework that addresses the concepts and details of the framework studied, as well as the diagnostic tools (throughput diagram and order progress diagram). Section 3 presents the research method detailing the case study and results. Section 4 deals with the conclusions of the case study and the direction for future research.

\section{Theoretical background}

\subsection{The tools used in the framework}

\subsubsection{Throughput diagram}

The throughput diagram is a tool to support the WLC methodology, which assists in the diagnosis of the delivery reliability and its purpose is to graphically describe the behavior of inputs and outputs cumulatively from a given work center over time. In addition to describing the input and output events of a particular work center, the throughput diagram can graphically represent the four production objectives over the time: inventories, utilization, lead times and lateness (Wiendahl, 1995).

The throughput diagram has become the most important means for describing complex production processes and is especially suited for visualizing the state of a process. In addition to being used for planning purposes, it is a general model of the production process that can be translated into mathematical means as shown in Figure 1. The throughput diagram can help to analyze the effects of applying the WLC

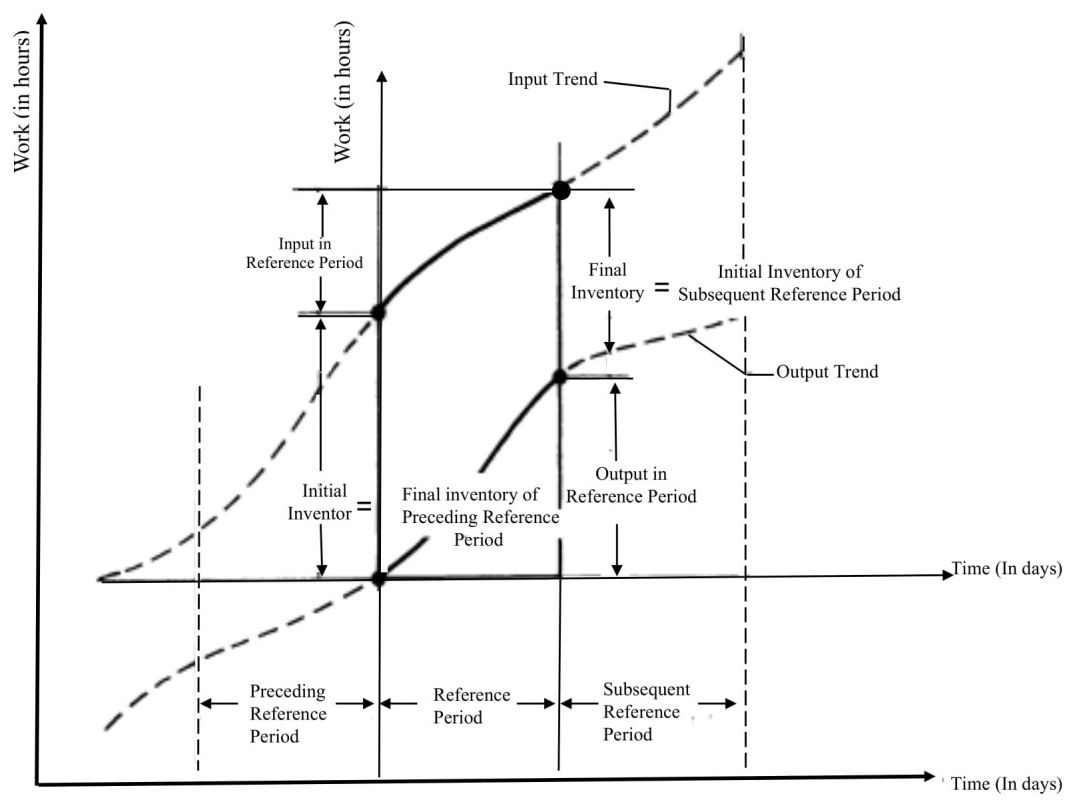

Figure 1. Principle of throughput diagram of a work center (Wiendahl, 1995). 
control mechanism to the adoption of central load balancing, which aims to reach small and constant buffers on the shop floor (Soepenberg et al., 2012a).

The throughput diagram represented by Figure 1 is particularly useful for insights when the decision on the average lateness should focus on the DP or RP discussed in more details in section 2.2. In Figure 1, the horizontal axis shows cumulative time in working days and the vertical axis shows, for each curve of the throughput diagram, the input and output of work in relation to a process flow of cumulative orders, where the work is measured in processing time hours.

\subsubsection{Order progress diagram}

The order progress diagram is a tool developed with the purpose of assisting in the explanation the variance of lateness, by relating the lateness of individual order to the progress of the order to the input and output control decisions of a certain process in the work center (Soepenberg et al., 2008).

Soepenberg et al. (2008) states that the order progress diagram indicates the difference between the progress of the individual orders and the average orders progress. In this way, we can analyze the orders that are delayed, and which are speeded up for each stage of the order. Besides, it is possible to extend this analysis of delay or speeding up and relate it to the estimated lateness. For each stage of the order the order progress diagram shows the relationship between realised individual throughput time and the average throughput time. Positive lateness occurs when the realization time exceed promissing delivery time (positive values) and negative lateness occur when the realization time are completed before the promissing delivery time (negative values). To illustrate the operation of the order progress diagram, Figure 2 is presented.

The horizontal axis in Figure 2 represents the calendar days (cumulatively), that is, it starts at day zero and extends until day $n$. The vertical axis shows the lateness in diferente stages of the process in days of an order. All dots above the horizontal axis are orders with a positive lateness, that is, orders that exceed the promissing delivery time (completed after the due date). On the other hand, the negative lateness are the orders completed before the planned date, that is, there was a speeding up of the order. It is also possible to observe that in the diagram there are dots above and others below the horizontal axis indicating a variance in the lateness (Soepenberg et al., 2008).

\subsection{Framework developed by Soepenberg et al. (2012b)}

This section presents the framework that supports the diagnosis of delivery reliability performance through a structured process. The diagnostic steps are followed sequentially in order to determine the relevant problem areas that background the delivery reliability performance. Where four main problems areas are distinguished, resulting from the four possible combinations of the average or variance of lateness on the one hand and the control of the DP or the RP on the other. The following is the sequence of steps proposed for the diagnosis of delivery reliability influenced by the PPC decisions, as shown in Figure 3.

\section{Step 1: Analyse the distribution of lateness}

The diagnosis starts by determining the percentage of orders delivered tardy in a certain period. For this purpose, quantitative data on promised delivery times and realised throughput times have to be gathered

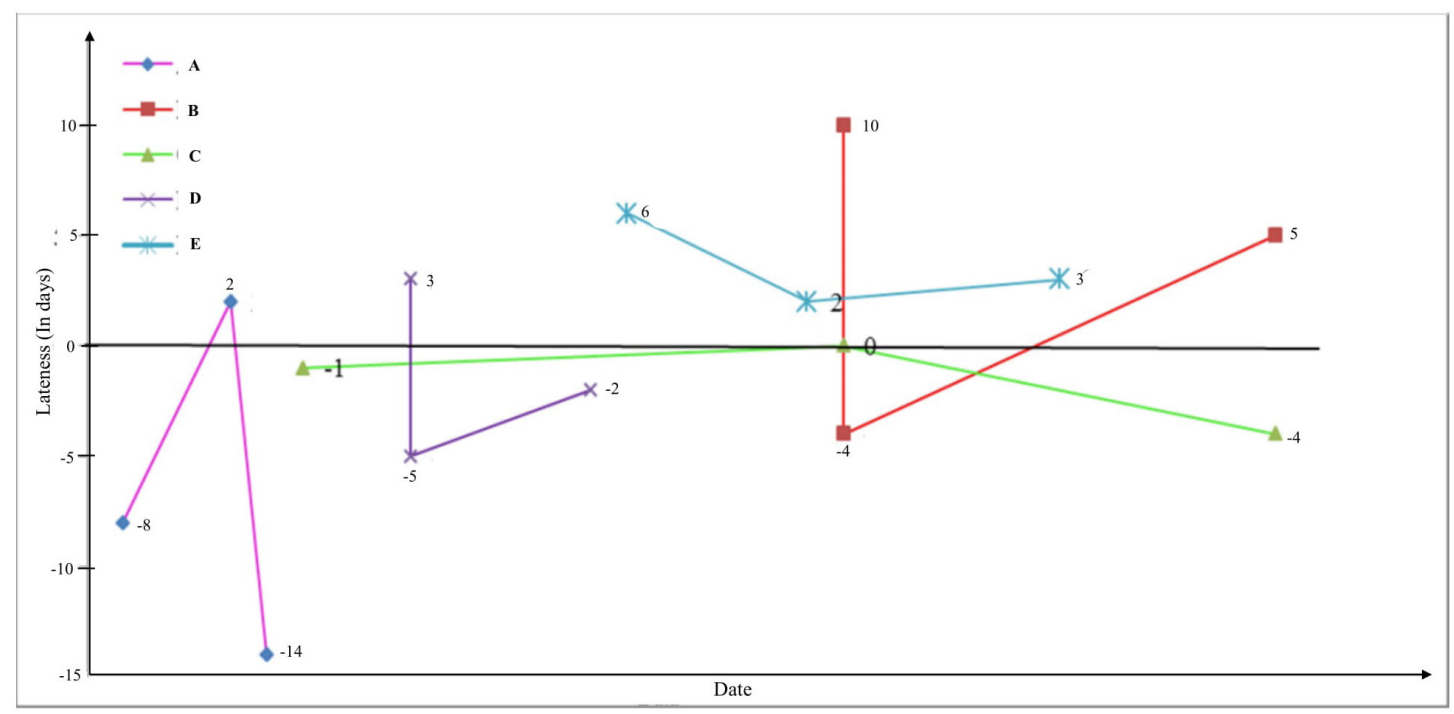

Figure 2. Order progress diagram of a production process. 
for the set of orders delivered in that period. Based on the lateness values of all orders, a distribution of lateness can also be constructed. The study of this distribution of lateness, as shown in Figure 3, can help in deciding whether to focus on the average lateness branch and/or the variance of lateness branch shown in Figure 3.

Step 2: Analyse differences among order subsets

When analysing the average lateness, one should check to see if a limited number of order subsets are responsible for the high average. This may allow one to narrow down the later analysis to these subsets. In terms of the variance of lateness, two situations may emerge:

(i) Some order subsets have a high internal variance of lateness which would lead to continuing the analysis of variance within these subsets;

(ii) The internal variance within subsets is limited and the variance of lateness is mainly the result of variance between subsets. In the latter case, the analysis should proceed by focussing on those subsets where the average lateness is high.

\section{Step 3: Analyse differences over time}

To gain insights into time dependency, the diagnosis continues by analysing how lateness changes over time. The throughput diagram and order progress diagram can be used in support for analysis is cicussed in detail in the fouth step of the diagnosis. The analysis of the mean lateness may reveal that specific time periods show relatively high lateness values compared to others, suggesting specific focus on these periods. In terms of variance, two situations may become apparent:

(i) First, if variance of lateness is mainly time-dependent, the diagnosis process may switch from analysing the variance of lateness to the average lateness. Here, the high average lateness in certain time periods becomes the focus of the analysis in the later steps;

(ii) Subsequently, if the variance of lateness is independent of time, the diagnosis continues along the branches related to the variance of lateness.

\section{Step 4: Analyse DP and RP}

Depending on the decisions made in the previous steps, the diagnosis will be either average-oriented or variance-oriented. The fourth step is to determine whether the diagnosis should continue in the process of DP and/or RP. Figure 3 presents the framework developed by Soepenberg et al. (2012b), which is the summary of the four steps presented in this subsection

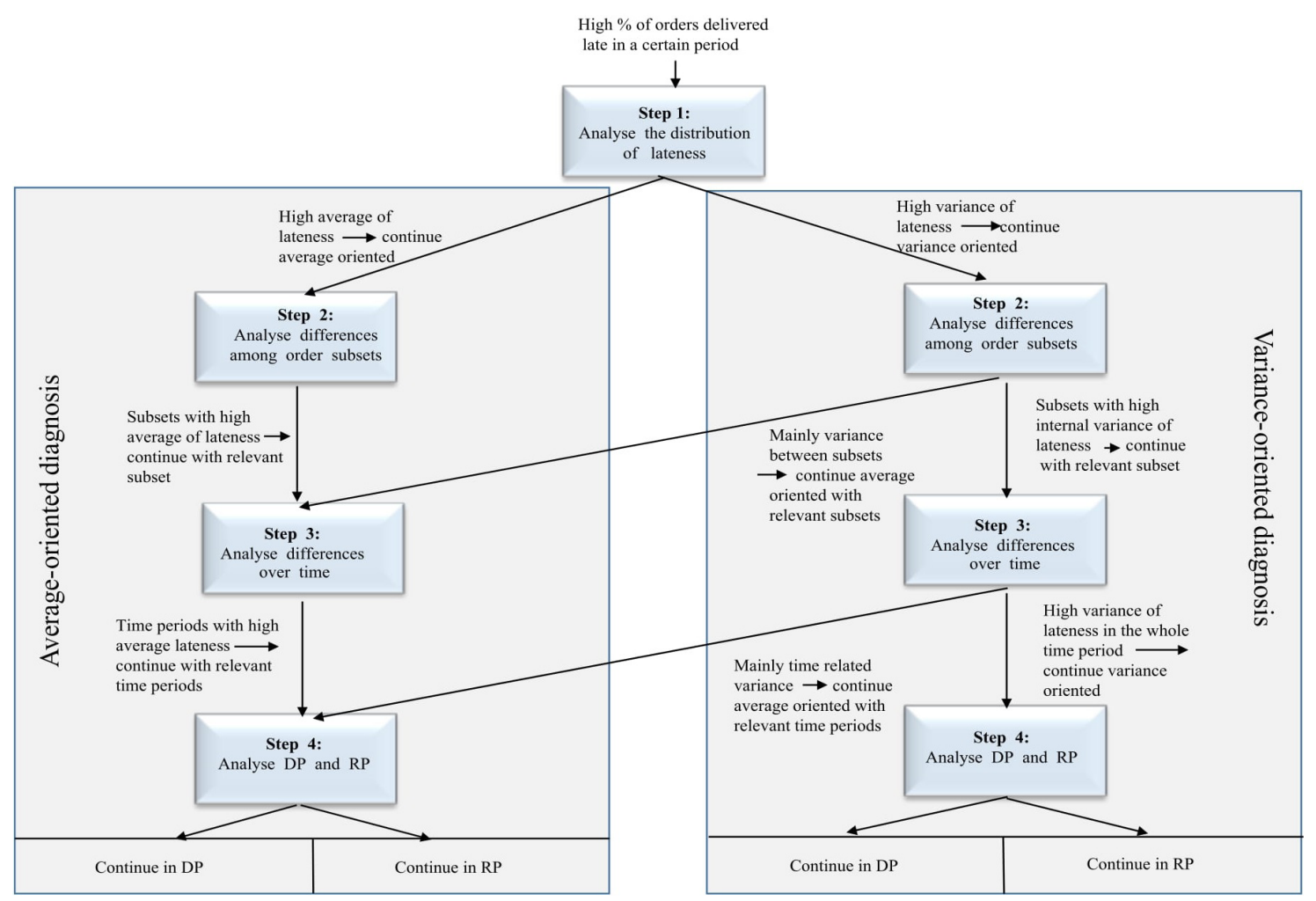

Figure 3. Framework to diagnose the lateness (adapted from Soepenberg et al., 2012b). 
The diagnosis provided by the framework implies guiding the lateness by the average or the variance. Thus, the final step is to determine whether the diagnosis should focus on DP or RP. This decision can be supported by the throughput diagram (Wiendahl, 1995) and the order progress diagram (Soepenberg et al., 2008). Figure 4 illustrates how these tools can be applied to decide which processes warrant future investigations and is explained in detail below.

\subsubsection{Average-oriented diagnosis: DP or RP?}

The throughput diagram represented by Figure $4 \mathrm{a}$ and $4 \mathrm{~b}$ is particularly useful for gaining insights, making the decision whether to focus on the DP or RP regarding the avarage lateness. In these graphs, the horizontal axis represents the time (dates) and the vertical axis shows, for each curve in the throughput diagram, the cumulative input and output of work regarding a process in the order flow. The work can be measured in units of orders or processing time units, the latter measurement being the most commonly used.

The curves can be plotted for each input / output moment of the flow of an order. At this stage of the diagnosis, an aggregate summary is sought with only two or three curves. The input curve (1) in Figure 4a and b refers to order acceptances. The cumulative output curve (2) refers to the order completions. These curves increase, respectively in value by the capacity requirements of the order at the time of acceptance or its completion. In addition, Figure $4 \mathrm{~b}$ shows a promising delivery date curve (3), which increases in value each time an order, is promised to be delivered to a customer. The vertical distance between the order acceptance curve and the completion curve (A) shows the Work-In-Process (WIP) in the company, and the horizontal distance (B) refers to the average throughput times of the RP. Similarly, (C) reflects the average of promised delivery times and (D) the average lateness.

According to Soepenberg et al. (2012b), an average lateness that would justify further investigation would be indicated in the diagram by an order completion curve (2) that lies close to or even below the promising output curve (3), over a considerable period of time, as shown in Figure 4b. Often, it is difficult to fully exclude either the RP or the DP, which respectively influence the order completion curve and promising output from further diagnosis. Nevertheless, some guidelines may be used to decide which of these processes to focus on.

An uncontrolled DP is often indicated by irregularities over time in the promissed output curve (3). This is shown in Figure 4 b, where there is a sudden shift at a certain time, resulting in a high average lateness (positive) from that time on. An uncontrolled RP can often be indicated by irregularities in the order (a)

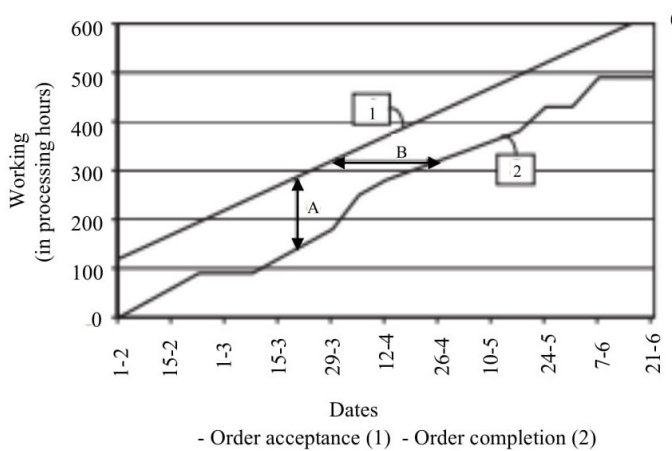

(b)

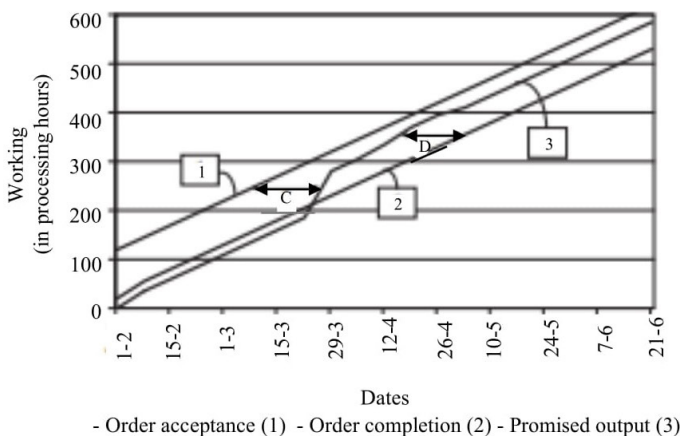

(c)

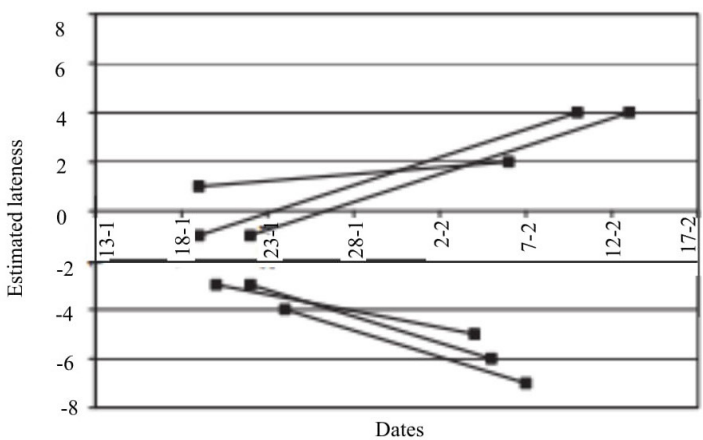

(d)

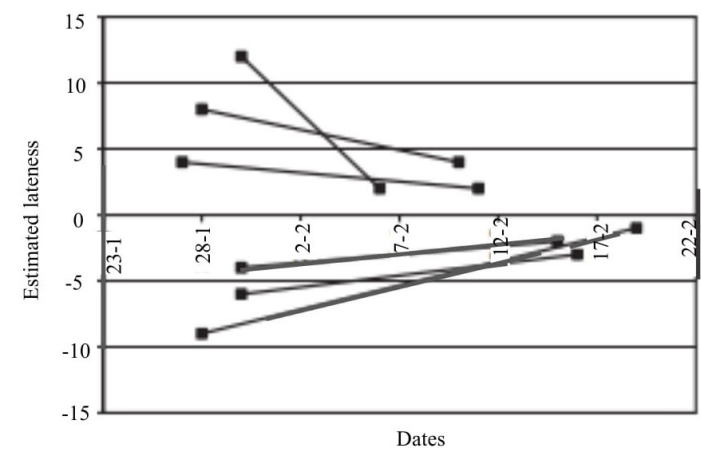

Figure 4. Key diagrams for diagnosis process (Soepenberg et al., 2012b). 
completion curve (as curve 2 in Figure 4a), unless these fluctuations follow the promised output curve.

It should be noted that although a stable level of the order completions may suggest adequate control of RP, but the average throughput times could be perceived as too long. For the pre-shop pool stage, this could be the result of the average delivery times of relatively long materials, while on the shop floor could result from unnecessary waiting often caused by excessive buffering.

\subsubsection{Variance-oriented diagnosis: DP or RP?}

The order progress diagram is a useful tool for a clear understanding of DP and PR regarding the variance of lateness. The horizontal axis in the order progress diagram measures the time, and the vertical axis indicates lateness. Each order is plotted as an individual curve in this diagram, which shows its progress from the start to the end of a process. Dots on the order curve indicate the start or completion of a process and can be included for each of the underlying processes in the RP.

Figure $4 \mathrm{c}$ and $\mathrm{d}$ both show the progress of six orders from their acceptance through to their completion. The horizontal positions of the left and right dots in each curve represents the time of acceptance and completion of the order, respectively. The vertical position of the left dot for each curve represents the lateness at the acceptance order in completion the order. The remaining dots represent the estimated lateness in relation to the order acceptance.

An estimated positive or negative lateness at acceptance indicates that an order would be delivered in late or early in relation to the promised delivery time. Orders with a positive and negative estimated lateness at acceptance (or at intermediate stages) and would commonly be referred to as urgent and non-urgent order respectively. Curves with an upward trend in the realization process are orders that are delayed in that process. Curves with a downward trend indicate orders that are accelerated. The left and right vertical axes indicate, respectively, the expected lateness variance in acceptance and the real lateness of the order of completion.
To decide whether to focus on the DP or the RP, a comparison of the variance of estimated lateness at the order acceptance and variance of lateness at order completion should be made this is illustrated using Figure $4 \mathrm{c}$ and $\mathrm{d}$.

Figure $4 \mathrm{~d}$ shows a situation in which the variance of estimated lateness is high at the time of acceptance. In this situation, the RP, while accelerating the most urgent orders, can not sufficiently compensate for the variability in the promised delivery times. This conclusion would address further investigation for DP.

Figure $4 \mathrm{c}$ shows a situation in which the variance of estimated lateness at the time of acceptance is relatively low. However, urgent orders are slowed down in RP, while less urgent orders are accelerated. As a result, the variance (estimate) in lateness increases during the RP, resulting in late delivery of some orders. This fact suggests an investigation focusing on RP.

\section{Case study}

\subsection{Research method}

In order to apply the framework by Soepenberg et al. (2012b), the case study method was used, because the justifications of Meredith (1998) and Yin (1989) are allied that points out that the case study is an excellent vehicle for the development of understanding when the subject is complex playing a fundamental role in this field. Stuart et al. (2002) presents the process of conducting the research that consists of four critical stages, illustrated in Figure 5.

The research question was defined after reviewed the literature as advised by some authors such as Eisenhardt (1989), Schmenner \& Swink (1998) and Stuart et al. (2002). From this, the research question was defined: "How the framework developed by Soepenberg et al. (2012b) based on the concepts of Workload Control can contribute to identify the delivery reliability problems associated with Production Planning and Control?"

The chosen workshops fall under the MTO feature set and customers put pressure on delivery times (aircraft on the ground is synonymous with loss).

Another determining factor for the selection of the company was the availability that it presented in

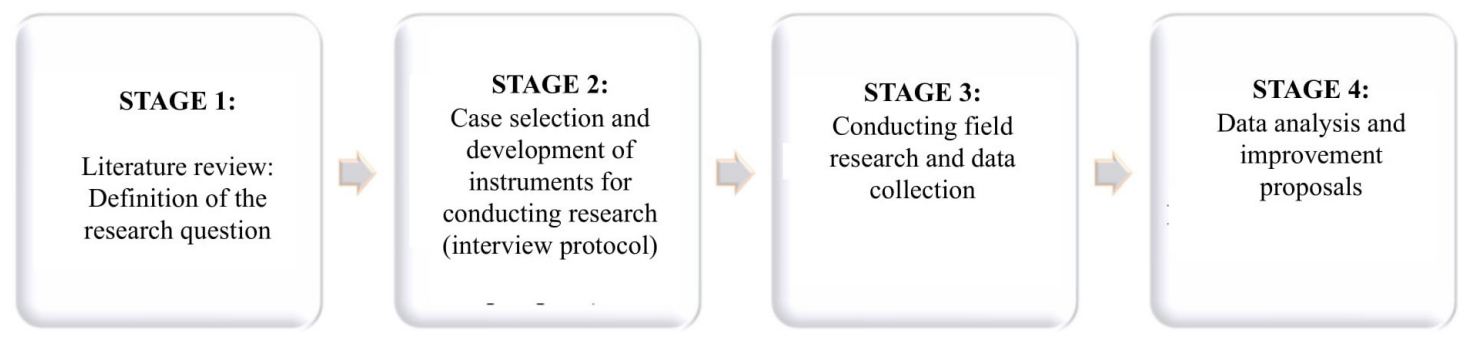

Figure 5. Stages for the development of the present research (Stuart et al., 2002). 
relation to the availability of data for the development of the research. The case study protocol used in this present research based on Yin (2010) and Voss et al. (2002) is found in Appendix A.

Data collection can be a complex and difficult activity, if it is not well planned and conducted all the research work can be harmed (Yin, 2010). This study used seven steps for an effective conduction of the data collection and validation of the present research and are summarized in Figure 6.

Regarding to data sources, this research used, as indicated by Barratt et al. (2011): semi-structured interviews; observation with technical visits; participation in meetings; organization chart documents; orders lateness records and; reports. The data sources were triangulated in order to increase reliability (Boyer \& McDermott, 1999; Hyer et al., 1999; Leonard-Barton, 1990) and to make the fundamentals and constructions of prepositions more robust (Eisenhardt, 1989; Voss et al., 2002).

Data analysis determines what was understood through the data and presenting them is an integral part of the researcher's task and can take a long time and effort. All data were tabulated and analyzed through spreadsheets.

\subsection{Characterization of the unit of analysis: the workshops}

The business unit studied is located in the interior of the State of São Paulo and has about 1.200 employees. The facilities have hangars that have the capacity to serve, simultaneously, seven aircraft allowing to attend more than 120 aircraft per year. Among the activities carried out by the unit studied are: aircraft maintenance; maintenance of components; training, line maintenance and supply of ground support equipment.

The computers workshop is responsible for the maintenance of 228 part numbers, that is, it carries out maintenance on 228 different parts and operates in three shifts, due to the restriction of equipment to perform a specific test. The electronic components workshop is responsible for the maintenance of 323 part numbers and operates in only one shift.

The maintenance components are received at the destination workshops and registered in the company's information systems. At this point in the process, the components wait in queue until they are started and are visible in the Maintenance Management System (MMS) reports. At the beginning of the maintenance process, registration is carried out in the information systems and the mechanic and / or technician responsible perform the entrance, cleaning and inspection of the conditions of the component. In relation to this activity two issues are defined: the materials needed for the repair of the item and the destination workshop. The process is detailed in Figure 7.

\subsection{Application of the framework in the computers workshop and the electronic components workshop}

This subsection is intended for application of the framework in the electronic components and computers workshop.

\subsubsection{Computers workshop}

According to Soepenberg et al. (2012b), the lateness analyzes follow the following steps:

Step 1: Analysis the distribution of lateness

This step consists in determining the percentage of orders delivered tardy in the period that covers the month of January 2013 and extends until May 2014. In order to comply with step 1, an analysis was performed on quantitative data of the orders referring to the dates estimated completion dates and the actual completion dates.

In step 1, it was found that the average the lateness of the 2.496 orders was 0.25 days and the standard deviation was 29.83 days and the maximum positive lateness was 345 days. Approximately $89 \%$ of orders are completed before the DD. Thus, we conclude that the order lateness is oriented by the variance,

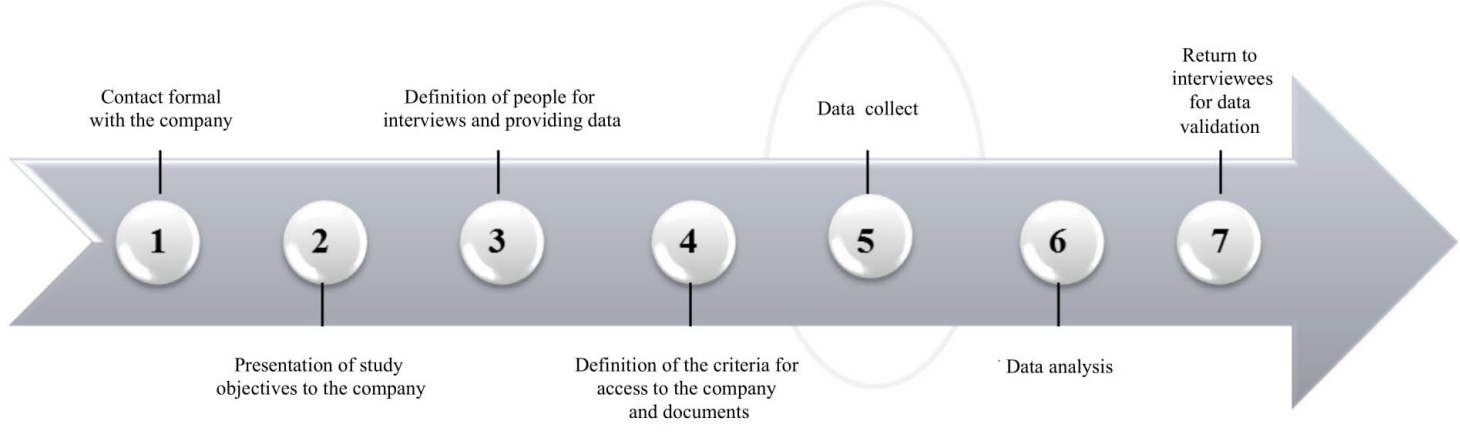

Figure 6. Summary of steps for the effective conduct of the case study data collection. 


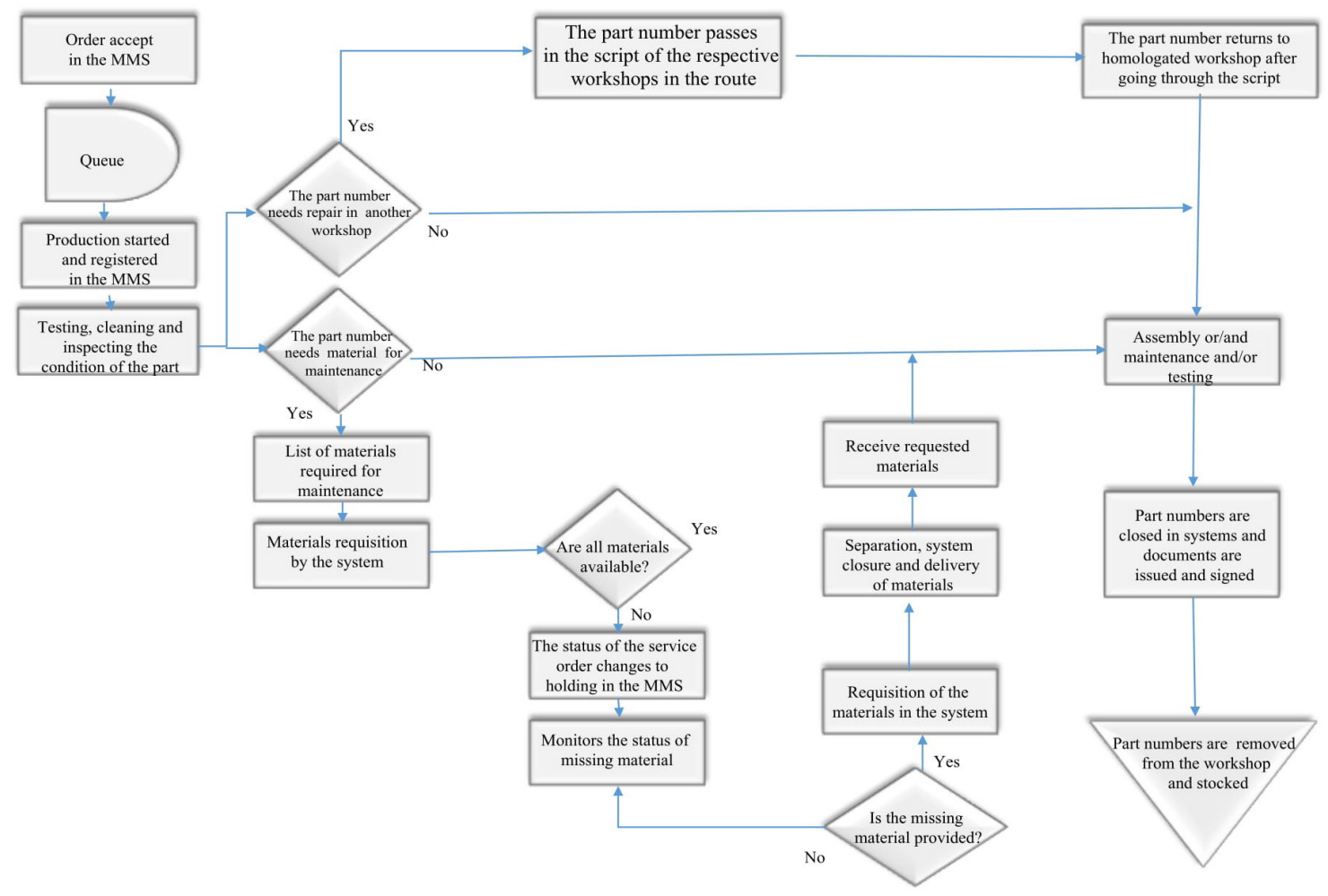

Figure 7. Simplified scheme of the process of maintenance of the part numbers in the workshops.

since we have an extremely low average lateness and a very high variability (coefficient of variance equal to 119,32 ).

Step 2: Analyse differences among order subsets

First, the causes of positive lateness were raised through interviews and documentary analysis. The result was that the large lateness was caused by lack of parts and this is not within the scope of the present study, since this depends on external suppliers to the company. By withdrawing the tardy orders for missing parts, the remaining orders total is 2.284 orders. Statistical analyzes for orders are given in Table 1.

Nevertheless, the mean value of the module is less than the standard deviation value and the analyzes continue to be oriented by the variance of lateness.

\section{Step 3: Analyse differences over time}

In the case in question, there is no point difference over time in relation to both positive and negative lateness, as illustrated in Figure 8.

Step 4: Analysis of DP and RP

As seen in the previous step, the diagnosis will be guided by the variance. In these cases, order progress diagram is the ideal tool to help the company decide on the focus on DP or RP (Soepenberg et al., 2008). As seen in Figure 4, the important part of the order progress diagram is the relationship between the lateness in arrival order and the lateness in completion
Table 1. Analysis considering the lead time established by the computer workshop.

\begin{tabular}{lc}
\hline \multicolumn{2}{c}{ Descriptive Statistical Analysis of lateness } \\
\hline Mean (days) & -7.20 \\
Standard deviation (days) & 10.12 \\
Sample variance (days) & 102.41 \\
Minimum (days) & -14.00 \\
Maximum (days) & 14.00 \\
Number of orders & $2,284.00$ \\
\hline
\end{tabular}

order. Figure 9 shows the maximum and the minimum of the possibilities of the lateness, both in the arrival and the completion of the orders.

The lines shown in Figure 9 represent the maximum and minimum limits within the order progress diagram. According to Figure 9, it is possible to observe that the variation of the lateness in the arrival of orders (37 days) is greater than the variation in the order completion (28 days), which leads to a focus in the DP (similar to Figure 4d).

In other words, planning the actual arrival of orders in production is not commensurate with those estimated by the Company's Operations Planning which leads to an initial planning and control error of the order and extends throughout the entire maintenance process. Thus, Figure 9 presents a situation in which the variance of the estimated lateness is already 


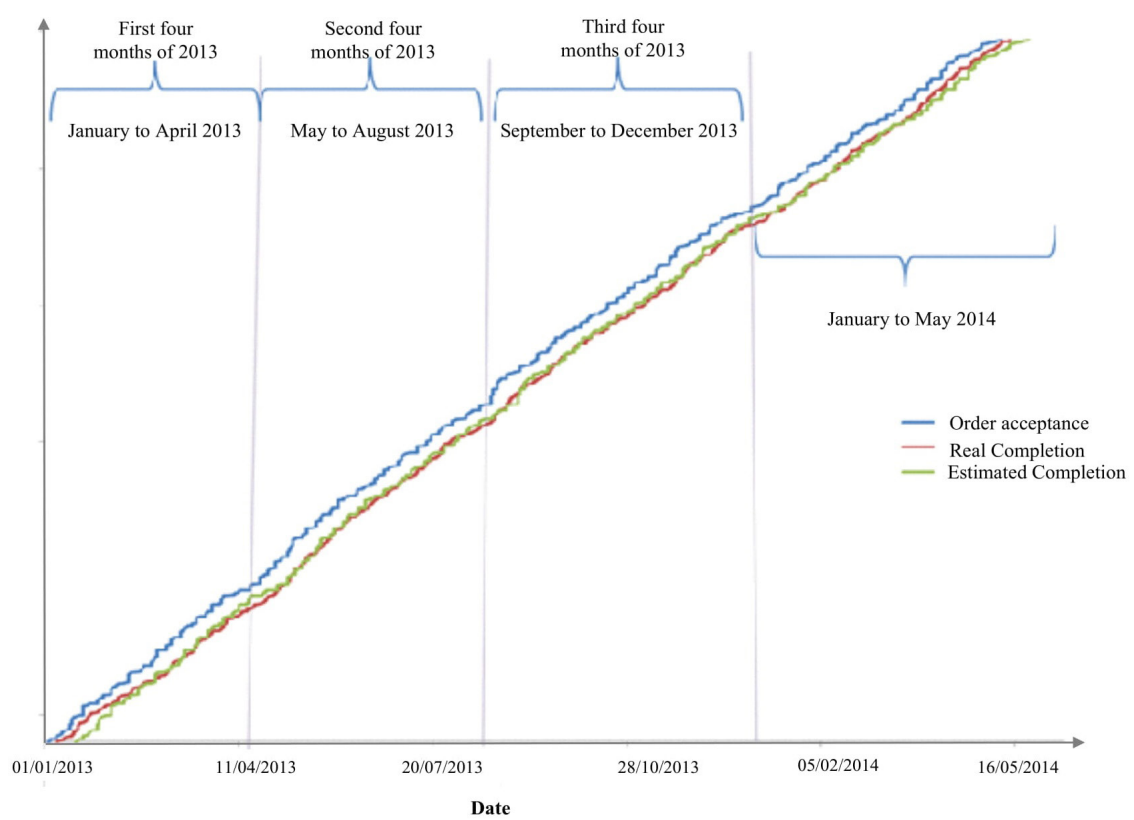

Figure 8. Throughput diagram of computers workshop lateness.

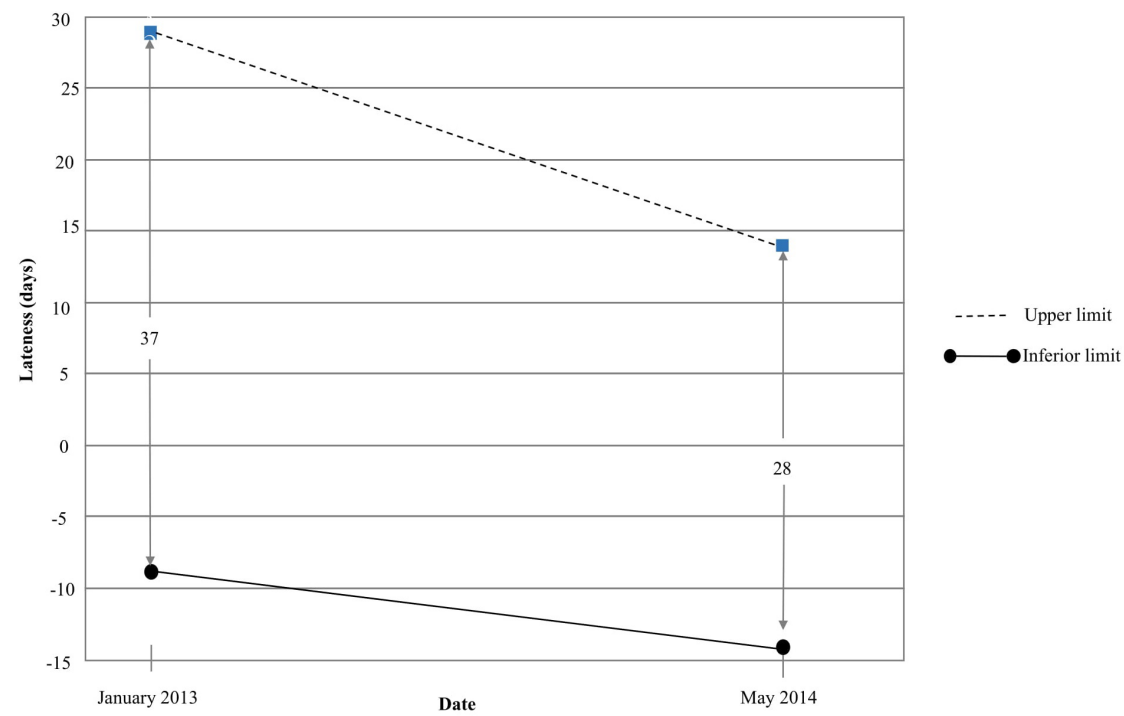

Figure 9. Order progress diagram of the simplified computers workshop.

high at the acceptandce time. In this situation, the order realization processes can not compensate for the variability in the promised time delivery. This conclusion makes the investigation with the focus oriented by DP.

The fact that approximately $89 \%$ of the orders are completed before the DD together with the variance of the lateness with a focus on DP makes us analyze the reason for the large number of orders concluded with anticipation. For this, an analysis of the estimated and utilized capacity according to 2.496 orders was carried out; that is, all the orders of the computers workshop were considered in the period that comprises this work (January 2013 to May 2014) and the results are presented in Table 2. Regarding capacity, it is important to point out that in this study it encompasses hours of labor and equipment capacity.

According to the analyzes of the estimated capacity versus utilized capacity summarized in Table 2, it is possible to verify that the company did not have a management of its workload capacity, for 10.998 hours are not used during the 15 months of analysis. Therefore, the review of the PPC methods used by the company through a more detailed analysis of the history for a more accurate determination of 
Table 2. Analysis of the estimated and used capacity of the computer workshop.

\begin{tabular}{lr}
\hline \multicolumn{2}{c}{ Capacity analysis } \\
\hline Utilized Capacity 2013 (hours) & 16,279 \\
Utilized Capacity 2014 (hours) & 7,555 \\
Estimated capacity 2013 (hours) & 25,116 \\
Estimated capacity 2014 (hours) & 9,716 \\
Difference between estimated capacity - & 8,837 \\
utilized 2013 (hours) & \\
Difference between estimated capacity - & 2,161 \\
utilized 2014 (hours) & \\
Estimated capacity percentage 2013 & $64.82 \%$ \\
Estimated capacity percentage 2014 & $77.76 \%$ \\
Idle capacity percentage 2013 & $35.18 \%$ \\
Idle capacity percentage 2014 & $22.24 \%$ \\
\hline
\end{tabular}

the arrival dates is necessary, in order to measure the waste of resources and as a consequence a high cost for the lack of management.

\subsubsection{Electronic components workshop}

Step 1: Analysis the distribution of lateness

Based on the lateness data of 7.229 orders, the average lateness value was $-4,17$ days and the standard deviation was 19,73 days. Thus, we conclude that the order lateness is oriented by the variance. Therefore, one must construct the order progress diagram. It can be said that the electronic components workshop a high percentage of orders completed before the DD $92,38 \%$. The next step is to create subsets, which allows an analysis of the difference between them.

Step 2: Analyse differences among order subsets

Step 2 consists of analyzing the differences between subsets. The orders of the electronics workshop were divided into positive lateness and negative lateness. Further analysis of the positive lateness was done by analyzing the production reports and it was found that the majority of the lateness are caused by the lack of parts $(81.39 \%)$ and other reasons $(18.61 \%)$.

Further analysis on the lack of parts of the computer shop reflects the same causes of the electronics component workshop. With regard to the so-called "other reasons" of the electronic components workshop, the causes were investigated through management reports and interviews. The reasons for the "other reasons" are the unavailability of the equipment, a limited number of employees with training to carry out maintenance, urgent orders, forgetting the part in the storage area, among others.

The same conclusion from the computers workshop was obtained in relation to the positive lateness. Thus, the causes of the positive lateness observed were not only the responsibility of the company's decisions but also a set of external factors that directly influence these problems in great magnitude. From this conclusion, it was decided to study further the question of orders with negative lateness.

It was found that the average lateness value of 6.661 orders was $-7,95$ days and the standard deviation is 2,98 days. Therefore, we conclude that negative lateness are averaged, since the mean module is larger than the standard deviation module. Considering this finding the appropriate tool to diagnose the problems would be the throughput diagram.

Step 3: Analyse differences over time

In this step, the lateness variation is independent of the time in the time horizon delimited by this study and it was found that, the lateness has no time-dependent relationship.

Step 4: Analysis of DP and RP

The fourth step of diagnosis consists of determining the focus of the problem, whether it is in DP or RP. As seen in the second step of the framework, the diagnosis will be averaged. In this case, the throughput diagram is the ideal tool to help the company decide on the focus on DP or RP (Soepenberg et al., 2012b). Figure 10 illustrates the results obtained with the use of this tool.

Figure 10 shows the behavior of the orders with respect to the acceptance, the estimated completion and the actual completion of the orders. From this, it is possible to verify that the actual completion curve is mostly above or near the estimated completion curve.

According to the data, it can be seen that the average crossing rate is 11,8 days and the WIP is equal to zero. The value of the WIP equal to zero reflects that the capacity available for the execution of the order, as well as the determination of the DD are optimal. However, when analyzing the average lateness, it is verified that the orders, on average, are finalized four days in advance. The values presented above, added to Figure 10 suggest the following assumptions:

(i) The maintenance process of the electronic components workshop is extremely efficient. Considering that, most of the tardy orders are caused by external factors such as lack of part;

(ii) Estimated completion times are too long due to excess capacity.

Item (ii) was formulated through the basic concept of WLC, which considers the capacity as a determining factor for the acceptance or rejection of the orders. The acceptance or rejection process is performed through capacity analysis. This analysis is based on the following points: if the available capacity is greater than or equal to the estimated capacity to carry out the order, it is accepted, otherwise the order is rejected.

The actual completion curve observed in Figure 10 was well above the estimated completion curve in the first three months of analysis and repeated this 


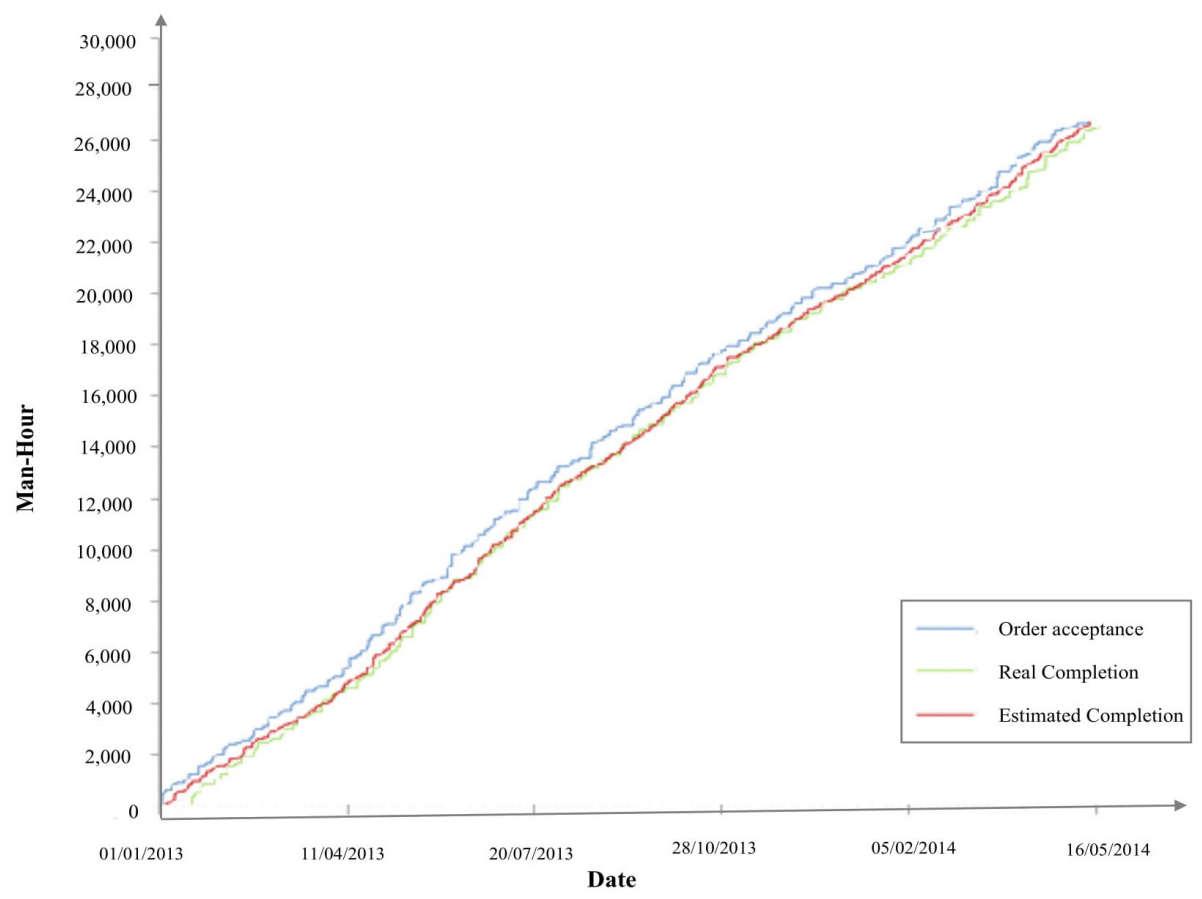

Figure 10. Throughput diagram of electronic components workshop lateness.

behavior over time. Thus, the irregularities in the order completion curve in the throughput diagram may indicate a focus on RP. However, according to Soepenberg et al. (2012b), if the actual completion curve follows the trend of the estimated completion curve the analysis of the lateness follows with focus on DP. The fact that more than $80 \%$ of the orders are completed before the DD together with the focus on the average lateness with focus on DP, causes the assumption (i) to be discarded. Since the focus on DP represents a lack of precision in determining the DD.

The focus on DP is with an analysis of the causes of negative lateness being raised in order to relate how the decisions of the PPC influence them. For this, an analysis of the estimated capacity and utized capacity according to the 7.229 orders was performed and the results are presented in Table 3 .

According to the analysis of the estimated capacity versus utilized capacity, in summary, Table 3 shows that the company does not estimate the capacity correctly, which results in a waste of resources. Therefore, the revision of the PPC methods used by the company to determine the order completion date is required. The starting point for improving accuracy in determining dates should be the most detailed analysis of the history in order to determine the arrival dates more precisely, in order to measure the waste of resources and as a consequence a high cost for the lack of management.

According to the analyzes of the estimated capacity versus utilized capacity presented in Table 3 , it is noted that 43.573 hours are not used during the 15 months of analysis.
Table 3. Estimated capacity analysis and utilized in the electronic components workshop.

\begin{tabular}{lc}
\hline \multicolumn{2}{c}{ Capacity analysis } \\
\hline Utilized Capacity 2013 (hours) & 51,571 \\
Utilized Capacity 2014 (hours) & 20,520 \\
Estimated capacity 2013 (hours) & 86,032 \\
Estimated capacity 2014 (hours) & 29,632 \\
Difference between estimated capacity - & 34,461 \\
utilized 2013 (hours) & \\
Difference between estimated capacity - & 9,112 \\
utilized 2014 (hours) & \\
Estimated capacity percentage 2013 & $59.94 \%$ \\
Estimated capacity percentage 2014 & $69.25 \%$ \\
Idle capacity percentage 2013 & $40.06 \%$ \\
Idle capacity percentage 2014 & $30.75 \%$ \\
\hline
\end{tabular}

\subsection{Analysis and discussion of the case}

The overview of the steps reached by the application of the framework for the analysis of the lateness of both workshops is presented in Figure 11.

The problems identified in the computers workshop and electronic components workshop through the application of Soepenberg et al. (2012b) are: lack of accuracy for determination of DP and lack of parts. Among the causes, it can be pointed out that the PPC does not have crucial information for the elaboration of the times and scripts of each part number that they pass in the workshops. Another cause observed is related to the restriction of the qualification of the employees. 


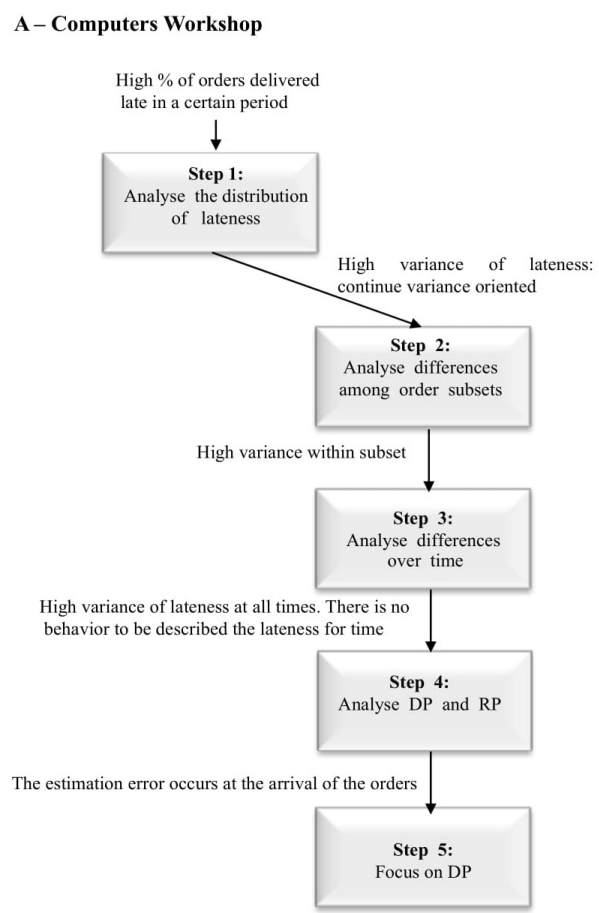

Figure 11. Overview of diagnostic steps and conclusions.

Although the computers workshop lateness is driven by variance and the electronic components workshop lateness are average, the lateness diagnosis for both has a focus on DP. This fact is justified because the workshops do not correctly estimate the arrival dates and do not have a maintenance schedule for each part number. In this way, both workshops estimate a fixed maintenance lead time without taking into account the different parts. In the case of the computers workshop, this period is 14 days and the electronic components workshop is 16 days.

An effect of the problems encountered is that the calculations for the workload capacity dimensioning in the workshops are not accurate due to the lack of information, creating a third problem. The information system used does not have a structure to support the activity of analysis and release of orders, according to criteria of priorities.

The scheduling task carried out by the PPC does not consider the prioritization of the orders and is unknown of the scheduling times, since it does not have information that is crucial for the elaboration of the sequencing. Another factor is that the three information systems used are not efficient, demanding great time. In some cases, the control is manual; and in others, it is necessary to give the input of the same information in the different systems, leaving the sequencing activities in the background.

The lack of parts to perform the services impacts on the delayed delivery of components by the production, since most of the parts are imported. The delays caused by the lack of parts are justified
B - Electronic components Workshop

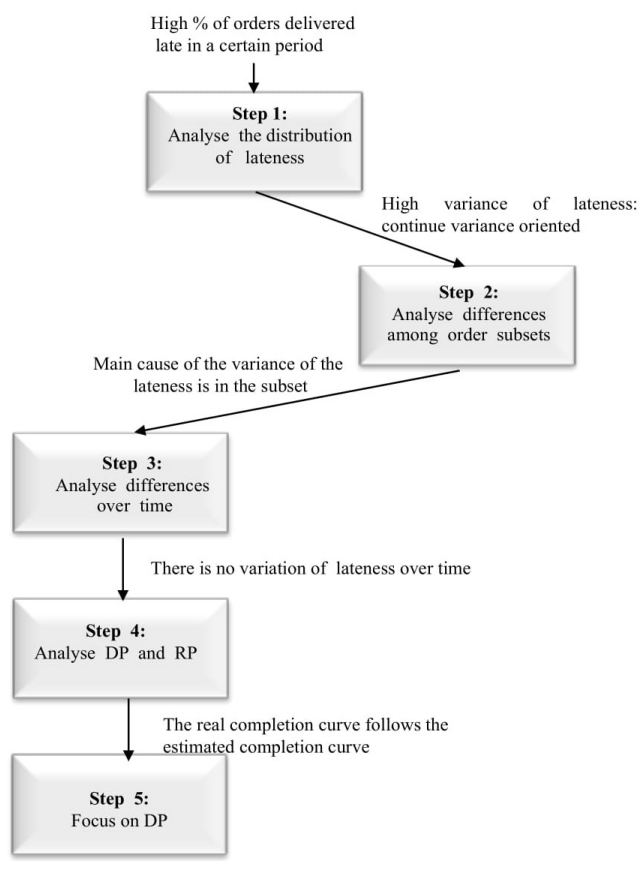

by the delays of deliveries by the suppliers, causing the work orders to be stopped. For this, the company works to its maximum capacity in order to cover up the uncertainties and inefficiencies processes. Inflated capacity is a strategic response to the lack of parts, due to inadequate information management. In this way, the inflated capacity generates a non-realistic due-dates and impairs capacity planning.

Therefore, of the two problems detected by the framework, most of the solutions are found in improving the information management of the departments responsible for planning and controlling the activities of these workshops. Once the information is organized in a database, it is possible to perform an accurate history analysis in order to obtain an effective action plan for problem detection and estimation of a more realistic lead time. This information management would solve the third problem: calculation error in determining the utilized capacity. The framework of Soepenberg et al. (2012b) presented with an important practical tool for the detection of problems related to delivery reliability.

\section{Conclusions}

The present study had as main objective to analyze how the framework proposed by Soepenberg et al. (2012b), which assists in the diagnosis of performance of delivery reliability influenced by PPC decisions. This objective was reached which identified the lack of materials, erroneous delivery time promising (DP) and excess capacity as the main causes of lateness. 
Soepenberg et al. (2012b) has developed the framework for small and medium enterprises characterized by being MTO. However, this research verified the applicability of the framework in a large company with MTO characteristics. Based on this finding, the framework can bring important contributions in the detection of problems in the delivery reliability in MTO companies in general.

The main advantage of the presented framework is an aggregate analysis of the behavior of the lateness in a certain period. This aggregation allows a more global analysis and facilitates the decision-making regarding areas of company improvement. In this work, the framework identifies two causes that are responsible for the orders lateness: problems in the realization of realisation processes (RP) or lack of precision in delivery time promising (DP).

The disadvantage found is based on step 2 of the framework, where the creation of subsets is not well defined. Depending on the characteristics of the productive system studied, the variables for grouping would not be possible. At this point, it is suggested that criteria be developed for the creation of subsets and, therefore, we recommend a more in-depth study of the framework adopted in this research in order to improve it.

The research was limited by being a unique case and only one type of productive system was analyzed through the framework. In addition, the lack of data availability of the releases of the orders caused a limitation in the research.

\section{References}

Barratt, M., Choi, T. Y., \& Li, M. (2011). Qualitative case studies in operations management: trends, research outcomes, and future research implications. Journal of Operations Management, 29(4), 329-342. http://dx.doi. org/10.1016/j.jom.2010.06.002.

Boyer, K. K., \& McDermott, C. (1999). Strategic consensus in operations strategy. Journal of Operations Management, 17(3), 289-305. http://dx.doi.org/10.1016/ S0272-6963(98)00042-4.

Eisenhardt, K. M. (1989). Building theories from case study research. Academy of Management Review, 14(4), 532-550. http://dx.doi.org/10.5465/amr.1989.4308385.

Hyer, N. L., Brown, K. A., \& Zimmerman, S. (1999). A socio-technical systems approach to cell design: case study and analysis. Journal of Operations Management, 17(2), 179-203. http://dx.doi.org/10.1016/S02726963(98)00034-5.

Kingsman, B., \& Hendry, L. (2002). The relative contributions of input and output controls on the performance of a workload control system in make-to-order companies. Production Planning and Control, 13(7), 579-590. http:// dx.doi.org/10.1080/0953728021000026285.

Leonard-Barton, D. (1990). A dual methodology for case studies: synergistic use of a longitudinal single site with replicated multiple sites. Organization Science, 1(3), 248-266. http://dx.doi.org/10.1287/orsc.1.3.248.

Meredith, J. (1998). Building operations management theory through case and field research. Journal of Operations Management, 16(4), 441-454998. http:// dx.doi.org/10.1016/S0272-6963(98)00023-0.

Schmenner, R. W., \& Swink, M. L. (1998). On theory in operations management. Journal of Operations Management, 17(1), 97-113. http://dx.doi.org/10.1016/ S0272-6963(98)00028-X.

Soepenberg, E. (2010). Workload control under diagnosis (Doctoral thesis). Universidade de Groningen, Groningen.

Soepenberg, G. D., Land, M., \& Gaalman, G. (2008). The order progress diagram: a supportive tool for diagnosing delivery reliability performance in make-toorder companies. International Journal of Production Economics, 112(1), 495-503. http://dx.doi.org/10.1016/j. ijpe.2007.06.001.

Soepenberg, G. D., Land, M. J., \& Gaalman, G. J. C. (2012a). Adapting workload control for job shops with high routing complexity. International Journal of Production Economics, 140(2), 681-690. http://dx.doi. org/10.1016/j.ijpe.2012.03.018.

Soepenberg, G. D., Land, M. J., \& Gaalman, G. J. C. (2012b). A framework for diagnosing the delivery reliability performance of make-to-order companies. International Journal of Production Research, 50(19), 5491-5507. http://dx.doi.org/10.1080/00207543.2011.643251.

Stevenson, M., Hendry, L. C., \& Kingsman, B. G. (2005). A review of production planning and control: the applicability of key concepts to the make-to-order industry. International Journal of Production Research, 43(5), 869-898. http:// dx.doi.org/10.1080/0020754042000298520.

Stuart, I., Mccutcheon, D., Handfield, R., Mclachlin, R., \& Samsons, D. (2002). Effective case research in operations management: a process perspective. Journal of Operations Management, 20(5), 419-433. http:// dx.doi.org/10.1016/S0272-6963(02)00022-0.

Thurer, M., \& Godinho, M. Fo (2012). Redução do lead time e entregas no prazo em pequenas e médias empresas que fabricam sob encomenda: a abordagem Workload Control (WLC) para o Planejamento e Controle da Produção (PCP). Gestão \& Produção, 19(1), 43-58. http://dx.doi.org/10.1590/S0104-530X2012000100004.

Voss, C., Tsikriktsis, N., \& Frohlich, M. (2002). Case research in operations management. International Journal of Operations \& Production Management, 22(2), 195219. http://dx.doi.org/10.1108/01443570210414329.

Wiendahl, H. (1995). Load-oriented manufacturing control. Berlim: Springer-Verlang. http://dx.doi.org/10.1007/9783-642-57743-7.

Yin, R. K. (1989). Case study research: design and methods (Applied Social Research Series, No. 5). Thousand Oaks: Sage Publications, Inc.

Yin, R. K. (2010). Estudo de caso: planejamento e métodos (4. ed.). Porto Alegre: Bookman. 


\section{Appendix A. Case study protocol.}

\section{Overview of the case study project}

This project describes the procedures required to conduct the case study in order to increase the research reliability.

The sources of the information provided in the interviewees to the researcher will be kept confidential. Neither the names of the people interviewed, nor the corporate name of the companies will be divulged. After study finalization, a copy will be provided to the company researched.

\subsection{Purpose of the case study}

The objective of the research is to apply the framework developed by Soepenberg et al. (2012b) in the electronic components whorkshop and computer workshop of an aeronautical maintenance industry. The framework in question has the purpose of analyzing of the orders lateness to diagnose the problems related to the delivery reliability coming from the Planning and Production Control (PPC) decisions.

The case study together with the literature review aims to elaborate proposals for improvements to the problems identified and to propose future research according to the identified gaps.

The main company characteristics for the application of the framework are:

- High variety of products;

- Low predictability of demand;

- Delivery reliability is an important competitive criterion;

- Information system that workshops the production time, the time of arrival and the time of completion by order;

- Information system with the description of the order;

- Information on capacity and workload per order;

- Company characterized should be characterized as MTO.

Therefore, the company that participates in the case study must present all or most of the characteristics mentioned above. Another requirement is that they are willing to provide the information necessary for the development of the research. People will be interviewed who have a knowledge of the organizational routine and, mainly, a deep knowledge of the productive activities of the studied company, in this case, will be the PPC analyst of the electronic components and computers workshop. The interviews will last a maximum of 2 hours and will be conducted by the researcher at the company's premises and a visit will be made to the company's premises.

\subsection{Research questions}

"What are the reasons for the lateness in completing orders at an aeronautical maintenance company identified through the application of a framework? "

\subsection{Relevant reading material for the case study}

\section{For the construction of the case study the relevant theoretical references are:}

- THÜRER, Matthias; STEVENSON, Mark; SILVA, Cristovao. Three decades of workload control research: a systematic review of the literature. International Journal of Production Research, v. 49, n. 23, p. 6905-6935, 2011;

- SOEPENBERG, G. D.; LAND, M. J.; GAALMAN, G. J. C. The framework for diagnosing the delivery performance reliability of make-to-order companies. International Journal of Production Research, v. 50, n. 19, p. 5491-5507, 2012.

\section{Procedures for data collection}

The procedure for collecting data from this study presents the data collection plan, the preparation for the visits and the interviewed members.

\subsection{Data collection plan}

The collection of data will be performed through scheduled interviews with the PPC Analyst of the selected company. The interviews will be scheduled by phone or email. The date for the interview will be proposed, but the interviewee will set the best date according to their availability.

Data collection will be performed through semi-structured interviews, observations in the company, analysis of the production reports extracted from the information system and in academic work carried out in the company.

\subsection{Preparation for interviews}

Two activities precede the interview:

- First, an e-mail will be sent to the interviewee with the general description of the study in order to contextualize the interviewees about the research topic; 
- Second, before the interviews are conducted, the information available on the company's website and in the academic work carried out in the company will be collected. These activities aimed at obtaining important information, which can be later discussed in the interviews.

\subsection{Field procedures}

The researcher should have a copy of the interview script handy and give the respondent another copy along with a cover page that presents the research. When the interviewee allows, it is advisable to use a tape recorder. Other cases should be taken notes during the interview. The topics to be discussed should be openly addressed to the respondents and no response should be exercised. However, other topics considered relevant and not included in the script can be explored by the researcher.

The maximum time allowed for interviews is 2 hours. However, depending on the availability of the person interviewed, this time can be reduced to at least 1 hour or elongated slightly. Very long and very short interviews should be avoided.

The researcher should, whenever possible, obtain concrete facts about the interviewee's answers and cross information with observations to be made in the visit to the premises and the company's presentation.

The material to be taken in the field research is the following: interview scripts, copies of the interview scripts for the interviewee, general data collection form, recorder and notepad.

\subsection{Interview roadmap for the case study}

Data Sources:

- PPC Analyst

- Topics to be covered in the interview:

- Characterization of the company studied;

- Characterization of the studied sector;

- Information system used;

- Ability to maintain aircraft in the company;

- What models of aircraft the company maintains;

- Certifications that the company has;

- Problems encountered by the PPC;

- Functions of the PPC in the company;

- Problems related to the maintenance process;

- Limitations during the maintenance process;

- Sources of components for maintenance;

- Component flow for maintenance;
- The relationship between PPC and delivery reliability;

- Determination of due dates;

- Other information that the researcher considers relevant;

- Complementary information from the interviewee.

After each interview, a summary of the interview should be written. The abstract should contain general information about the interviewee's name, his/her position, date of interview, company and length of interview. This information should be entered early in the summary. Next, a summary of the interviewee's opinions should be made following the sequence of the interview script. When the interview is recorded, you should transcribe relevant excerpts from the interview.

After the visit to the company's premises and the presentation of the productive system by the company, the researcher must write a summary of his observations of items to be observed and those he considers relevant for the research.

Then, after the completion of the interviews, the writing of the interview summaries and the field observations, the researcher must write the case study report. This report will be divided into five major blocks:

- General data;

- Organizational aspects;

- Relevant aspects;

- PPC and;

- Interviews.

In relation to the general data must include information such as: branch of activity of the company, location, market share, number of employees and certifications.

On the organizational aspects should be reported the observations of the researcher on the typical organization of the production of the company, hierarchical structure.

In terms of relevant aspects should be reported the observations about PPC or organization of production that is important for the performance of the company's delivery reliability, has provided a major change or is related to the research question.

In the PPC block, a brief report on the investigator's observations on PPC should be made in conjunction with the analysis of the production reports provided by the company.

Finally, in the block of interviews should be consolidated the summaries of the interviews made in the case study, naming the interviewee by his position. Consolidation should be done according to the topics of the interview script. 